\title{
GP led commissioning: time for a cool appraisal
}

The government has identified GP led commissioning as critical to tackling the twin challenges of service change and improved efficiency, but does the evidence bear this out? Judith Smith and Nicholas Mays investigate

\author{
Judith A Smith head of policy ${ }^{1}$, Nicholas Mays professor of health policy ${ }^{2}$ \\ 'Nuffield Trust, London W1G 7LP, UK; ${ }^{2}$ London School of Hygiene and Tropical Medicine, Department of Health Services Research and Policy, \\ London, UK
}

General practitioner led commissioning is a policy with which the English NHS has held faith since 1991. The establishment of over 250 clinical commissioning groups comprised primarily of general practitioners (GPs) represents a central plank in the English NHS reform programme currently being debated in parliament. ${ }^{1}$ It is proposed that from 2013, commissioning groups will gradually assume responsibility for $£ 60 \mathrm{bn}(€ 72 \mathrm{bn}$; $\$ 95 \mathrm{bn}$ ) of funding from primary care trusts when they are abolished and be accountable to a NHS Commissioning Board. We use the evidence on previous GP led commissioning initiatives to highlight the likely limitations of new commissioning groups and suggest some changes.

\section{What is GP commissioning meant to solve?}

The perpetual desire to strengthen commissioning reflects frustration at the seeming failure of different purchasing arrangements to shift care from hospital to community settings and reduce the rates of avoidable emergency admissions. ${ }^{2}$ Instead the NHS has seen an inexorable rise in emergency admissions over the past decade ${ }^{3}$ and an expansion of secondary care spending and activity. ${ }^{4}$

The desire to halt this trend and develop alternative forms of care, especially for frail older people with complex conditions, is now stronger than ever. The NHS faces an unprecedented $4 \%$ efficiency target for each year until 2015. GP led commissioning is a key part of government plans to meet these challenges.

\section{What is the rationale?}

The rationale for GP led commissioning is that GPs, given their gatekeeping role in relation to expensive secondary care and diagnostics and knowledge of patients on their practice lists, are well placed to purchase health services on behalf of the local population. They are considered to combine an individual patient focus with a broader population perspective. ${ }^{5}$ The theory is that by holding budgets for referral and treatment decisions, they can be encouraged to develop the more community based care that has so far eluded the NHS. This belief is rooted in wider analysis of the value of involving clinicians in the management of health services. ${ }^{6}$ The downside is that devolved purchasing increases transaction costs, loses the economies of commissioning at scale, and makes it harder to manage financial and service risk. ${ }^{7}$ Furthermore, GPs will also become responsible for rationing local healthcare and have to account for difficult investment and service decisions. The primary-secondary care divide of the NHS is also perpetuated, and the thorny issue of who commissions and improves primary care remains unresolved. $^{8}$

\section{What does the evidence tell us? Commissioning needs to engage GPs while
assuring transparency of interests}

History has shown that while GP commissioners start with a strong desire to be nimble clinically focused organisations, they are usually rushed by policy makers into becoming larger statutory bodies with wide ranging responsibilities and are then deemed bureaucratic and distant from local professionals. This happened with primary care groups and primary care trusts, ${ }^{9}$ and a fundamental issue for clinical commissioning groups is how to avoid this process and stand a chance of maintaining the engagement of GPs and other clinicians.

GP commissioning requires local family doctors to sign up to a minimum set of activities, including working to common protocols for referral for specialist opinion; sharing of clinical and activity data; adherence to collectively agreed pathways of care for long term conditions; and abiding by local policies for prescribing drugs and diagnostic tests. ${ }^{10}$ Research highlights the importance of crafting an appropriate balance of incentives for GPs and avoiding overly burdensome governance that risks GPs perceiving commissioning groups as belonging to the state rather than local doctors. ${ }^{11}$ However, GPs also face inherent conflicts of interest when deciding whether to "make or buy" local health services that can be provided by general practice, services in which they are likely to have a personal financial interest. ${ }^{12}$ One 
way to achieve this would be for a subset of local GPs to take on the role of formal commissioners of healthcare for the local population. This role could be separated from that of smaller collectives of other local GPs taking on budgets for managing chronic disease and extended primary care, with the possibility of using any savings to reinvest in local services.

\section{Commissioning will struggle to make a difference beyond primary care}

Evidence shows that GP led commissioners focus foremost on the development of primary care, this being of most direct relevance to general practice teams. Examples include the provision of specialist community nursing care; new primary care based diagnostic services; and services to support people living with long term conditions. A comprehensive review of primary care led commissioning found little evidence of impact on the way that hospital care was delivered, except in encouraging some increase in responsiveness of services, such as shorter waiting times or improved information from hospitals to GPs about treatment of their patients. ${ }^{7}$

Subsequent analyses have confirmed this, ${ }^{2} 1213$ challenging current proposals to make GP led commissioning the main vehicle for health purchasing and relying on it to bring about major service change at a time of tough financial constraint. As with total purchasing pilots in the late $1990 \mathrm{~s},{ }^{14} \mathrm{GP}$ led commissioners continue to report difficultly in changing acute care contracts and funding flows and seem drawn to concentrate on those services that they know and can control best. ${ }^{212}$

Possible levers to help with this task include continuing the reform of the NHS payment system to enable commissioners to bundle payment across primary and secondary care services; clear national standards for urgent and chronic care, developed and implemented by the Commissioning Board; and the use of greater supply side competition to make providers more responsive to commissioners' wishes. Furthermore, it is worth experimenting with the allocation of population based budgets to groups of primary (and ideally also secondary) care clinicians seeking to develop integrated care, making them jointly accountable for managing and improving services such as urgent and chronic disease care. ${ }^{15}$

\section{Extensive management support will be needed}

Commissioning is hard to do, in whatever form. ${ }^{8}{ }^{16}$ It requires sophisticated support, such as needs assessment, modelling of demand for future care, service specification, contracting and procurement, and assessment of service quality and outcomes. Some studies have highlighted a link between levels of management support and progress in terms of commissioning outcomes. ${ }^{14}$ Recent analysis by a leading US commentator points to the need to invest heavily in management support if devolved commissioning in the NHS is to succeed, ${ }^{17}$ a point also made in a review of NHS commissioning in $1998 .{ }^{8}$ However, the NHS currently faces a reduction in management costs of over $40 \%$, making it likely that such support will be hard to find.

With the removal of primary care trusts and strategic health authorities, commissioning groups will be left with a daunting range of responsibilities. Critical to success is recognising that there is a continuum of commissioning from the individual to national scale (figure $\downarrow$ ), with financial and service risk allocated according to the scope and scale of a particular service. Commissioning groups might decide what risk they are ready to handle, but they will need to be held to account for this by the Commissioning Board through its proposed process for authorising commissioners. ${ }^{18}$ Commissioning support is therefore likely to be shared across commissioning groups and other organisations, with different arrangements for services according to the level of financial risk, building on the existing spectrum of support arrangements developed for primary care trust and practice based commissioning, and mitigating the known diseconomies of scale inherent in devolved purchasing.

Without such support, commissioning groups will be unable to make much more than marginal changes to local services, and any change is likely to be mainly in primary rather than secondary care.

\section{Governance and accountability will prove tricky}

Good practice in the governance of public organisations requires that funds are spent in an accountable and transparent manner. GP led commissioners have found it difficult to develop effective arrangements for accountability to the public and patients. ${ }^{14}{ }^{19}$ Likewise, it has been shown that nurses and other non-medical staff struggle to have a meaningful influence on the decisions taken by GP commissioners. This poses a significant risk that decisions may be made without the debate expected of public funding bodies, GPs' views may dominate even where other clinicians are involved, and there may be inadequate mitigation of the conflicts of interest inherent in GPs making decisions about the funding of local health services.

Commissioning groups will thus need carefully crafted governance arrangements that can build public and professional confidence in their decisions and of their GPs as advocates for their patients, while securing necessary buy-in from GPs and other clinicians. Groups need to operate as fully fledged public bodies capable of withstanding judicial review of what may prove to be contentious funding and service development decisions. There will also need to be robust arrangements for the local commissioning and performance management of primary care provision, developed in concert with the Commissioning Board. Proposed amendments to NHS legislation set out requirements for lay and specialist clinical involvement in governance. Putting these in place, and simultaneously engaging frontline clinicians in commissioning, is a big challenge.

\section{Way forward for reform}

English NHS policy is unusual in its attachment to the idea of GPs leading the purchasing of healthcare at local level. The evidence suggests that GP led commissioners will find it extremely difficult to move beyond the incremental development of community services and engage their general practice colleagues in setting wider funding priorities and making substantial change to secondary (and also primary) care. To stand a reasonable chance of success the focus should be placed on how GPs can be central to reshaping the provision, rather than commissioning of local health services.

One solution is to take forward experiments with what has been termed a local clinical partnership ${ }^{20}$ or an integrated care organisation ${ }^{15}$ - where a funder (primary care trust cluster, outpost of the NHS Commissioning Board, or a subset of local GPs acting as the formal commissioning group) would allocate a population based budget to a collective of GPs and other clinicians with which to deliver a range of services for local people. This would entail a departure from what has, for two decades, been understood as GP commissioning. Research evidence, together with modern care and financial needs, makes 
such a rethink about the realistic potential of GP commissioning timely.

Contributors and sources: JAS and NM have both carried out extensive research and policy analysis in healthcare commissioning, medical groups, and primary care led commissioning. This article draws on research evidence on GP involvement in commissioning in the UK and elsewhere over 20 years. JAS had the idea for the article and prepared the first draft. NM commented on and edited subsequent drafts. JAS is the guarantor.

Competing interests: Both authors have completed the ICJME unified disclosure form at www.icmje.org/coi_disclosure.pdf (available on request from the corresponding author) and declare no support from any organisation for the submitted work; no financial relationships with any organisations that might have an interest in the submitted work in the previous three years (other than having received funding for independent health services research from the Department of Health Policy Research Programme and the National Institute of Health Research); and no other relationships or activities that could appear to have influenced the submitted work.

Provenance and peer review: Not commissioned; externally peer reviewed.

1 Department of Health. Equity and excellence: liberating the NHS. DH, 2010.

2 Smith JA, Curry N, Mays N and Dixon J. Where next for commissioning in the English NHS? Nuffield Trust, King's Fund, 2010.

3 Blunt I, Bardsley M, Dixon J. Trends in emergency admissions in England 2004-2009. Nuffield Trust, 2010.

4 Audit Commission. More for less? Are productivity and efficiency improving in the NHS? Audit Commission, 2009
5 Ham C. Population centred and patient focused purchasing: the UK experience. Milbank Q 1996;74:2:191-214

6 Baker GR, MacIntosh-Murray A, Porcellato C, Dionne L, Stelmacovich K, Born K. High performing healthcare systems: delivering quality by design . Longwoods, 2008.

7 Smith JA, Mays N, Dixon J, Goodwin N, Lewis RQ, McClelland S, et al. A review of the effectiveness of primary care-led commissioning and its place in the NHS. Health Foundation, 2004.

8 Light D. Effective commissioning: lessons from purchasing in American managed care. London: Office of Health Economics, 1998.

9 Smith JA, Walshe KMJ. Big business: the corporatization of primary care in the UK and the USA. Public Money Manag 2004;24:87-96.

10 Smith JA, Dixon J, Mays N, Goodwin N, Lewis RQ, McClelland S, et al. Practice-based commissioning: applying the evidence. BMJ 2005;331:1397-9.

11 Locock L, Regen E, Goodwin N. Managing or managed? Experience of general practitioners in English primary care groups and trusts. Health Serv Manage Res 2004;17:24-35.

12 Curry N, Goodwin N, Naylor C, Robertson R. Practice-based commissioning: replace, reinvigorate or abandon. King's Fund, 2008.

13 Audit Commission, Healthcare Commission. Is the treatment working? Progress with the NHS system reform programme. Audit Commission, 2008.

14 Mays N, Wyke S, Malbon G, Goodwin N, eds. The purchasing of health care by primary care organisations: an evaluation and guide to future policy. Open University Press, 2001. 15 Goodwin N, Smith JA, Davies A, Perry C, Rosen R, Dixon A, et al. A report to the Department of Health and NHS Future Forum: integrated care for patients and populations: improving outcomes by working together. King's Fund, Nuffield Trust, 2012.

16 Figueras J, Robinson R, Jakubowski E, eds. Purchasing to improve health system performance. Open University Press, 2005.

17 Casalino L. GP commissioning in the NHS in England: ten suggestions from the United States. Nuffield Trust, 2011.

18 Department of Health. Developing clinical commissioning groups: towards authorisation (draft) . DH, 2011.

19 Dowling B, Glendinning C, eds. The new primary care, modern, dependable, successful Open University Press, 2003

20 Smith JA, Wood J, Elias J. Beyond practice-based commissioning: the local clinical partnership. Nuffield Trust, NHS Alliance, 2009.

Accepted: 24 January 2012

Cite this as: BMJ 2012;344:e980

@ BMJ Publishing Group Ltd 2012 


\section{Figure}

\begin{tabular}{|c|c|c|c|c|c|c|}
\hline Individual & Practice & Multi practice & Local & Community & Regional & National \\
\hline $\begin{array}{l}\text { Personal } \\
\text { health } \\
\text { budgets }\end{array}$ & $\begin{array}{l}\text { Single } \\
\text { practice } \\
\text { based }\end{array}$ & $\begin{array}{c}\text { Multi } \\
\text { practice } \\
\text { or locality }\end{array}$ & $\begin{array}{c}\text { Joint } \\
\text { commissioning } \\
\text { with local }\end{array}$ & \multirow{2}{*}{$\begin{array}{c}\text { Primary } \\
\text { care trust } \\
\text { commissioning } \\
\text { and whole } \\
\text { primary care } \\
\text { trust practice } \\
\text { based } \\
\text { commissioning }\end{array}$} & \multirow{2}{*}{$\begin{array}{l}\text { Lead practice } \\
\text { based } \\
\text { commissioning } \\
\text { acute and } \\
\text { specialised } \\
\text { commissioning }\end{array}$} & \multirow[t]{2}{*}{$\begin{array}{c}\text { National } \\
\text { specialised } \\
\text { commissioning }\end{array}$} \\
\hline & & & & & & \\
\hline
\end{tabular}

Continuum of commissioning before the election of the current government ${ }^{7}$ 